\title{
Priming E-governance for Quality of Growth
}

\author{
Nyayapati V.L.N. Balramdas and Gade Lakshmi \\ Pune, India \\ nvlnb@vsnl. com \\ lax_g_2000@yahoo.com
}

\section{Introduction}

e-Governance woven around development missions and goals can open up potential business opportunities that complement and compete in enabling those in the business of Governance help deliver quality of life to the masses. The role of Knowledge Management $(K M)$ in these endeavors is both strategic and value enhancing. With the declining role of Governments, e-Governance can attract private entrepreneurship, eg, KM-embedded business models can be developed as Governance Technology Ventures. This Paper seeks to identify some approaches to structuring knowledge-based e-Governance tools, keeping in view a vareity of governance processes required for achieving quality of life (hence growth) outcomes in developing countries.

Strategic e-Governance: Strategic e-Governance is different from the run-of-themill, routinized, low-end e-governance. The traditional view that Governance is a confluence of processes targeted to achieve desired ends, however, continues to hold sway among development economists. There is a realization, however, that development interventions, framed in ivory towers and cast in a one-size-fits-for-all mold are far removed from ground realities. Implemented top down, they just do not work. The World Bank's Comprehensive Development Framework (CDF) underlines these insights, and recommends grass-roots approaches.

KM in Governance: The public sector, having realized the strategic importance of tools and concepts for managing their knowledge resources, is particularly poised for a take-off in practising KM. In the private sector, KM has been discussed for nearly a decade. Advanced concepts and systems supporting KM are being developed by companies who perceive and appreciate the added value of KM as a strategic instrument. Interactive, KM-based research and development (R\&D) in Governance Technology has a key role to play in futuristic Governance ventures

If we consider how a development plan (be it drafting a vision statement or a charting growth path) is to be introduced as a planned public policy intervention (PPI), how it is implemented, -- and try to gauze at what level of disaggregation (viz., the remit of Governance Structures/ Administrations) would such a PI be right --, it entails a thorough knowledge of the development issues at hand and of technology, i.e, how Governments must deal with them. In such contexts, "KM-based e-gov tools" can offer an assortment of solutions. However, neither development nor KM is instant coffee. The mix of ingredients in planned interventions need to balanced using an array of endowment and environmental (market) factors, and applied at the right time, in right dosages, and in properly diagnosed/ pre- identified catchment areas. In 
knowledge societies, such "catchments" do not necessarily be geographically contiguous, posing problems of dealing with complexity. KM thus has a pre-eminent role to play in the variegated strategic e-governance contexts cited above.

$R \& D$ in Governance Technology: Integrated Systems and Web-enabled KM approaches capable of dealing with the macro-to-micro complexity of policy-making and implementation can enable spread effects to trickle faster. They can help usher in an era of sustainable Quality of Growth $(Q O G)$ for developing countries, an area lately under microscope with World Bank research $<1>$ ) $\mathrm{KM}$ in e-Gov can work wonders to eradicate poverty, co-terminus with a QOG and development ethos. Inevitably, e-Governance will in future evolve more as a "knowledge management service", and become adaptive, personalized, proactive and accessible from a broader variety of devices. Communication services, as a consequence, need to evolve into collaborative services providing better support for argumentation (policy debates), negotiation (bottom-up planning), deliberation and other goal-directed forms of structured discourse (inclusiveness eg., gender, empowerment, grass-roots participation etc.)

Exploring the scope for e-Governance models based on Monitoring and Evaluation (M\&E) approaches to gauge development effectiveness represents an important task in QOG targeting. Seen from a KM lens, the kind of M\&E efforts entailing from KM in an assortment of multi-dimensional development contexts demand a balanced calibrated approach. Sensitizing politicians to the economic consequences of policy quick fixes, and more so in the management and governance of emerging technology driven sectors for securing poverty eradication and QOG outcomes is of paramount importance in this context. This Paper attempts to articulate these issues, with a view to prompting policy makers to create enabling environments that help permeate " $Q O G$ consciousness". In the authors' view, this is tantamount to "commuting the growth process", a chance to leapfrog into an era of quality of life at least for some poor, bypassing an unending saga of travails and tribulations that has been the plight of the third world poor, especially those from South Asia

\section{Priming E-governance for Quality of Growth}

At the dawn of the 21st century, we are beginning to grapple with the reality of what until recently have been mere concepts - the Information Age, Knowledge Society, Knowledge Management (KM) etc. These concepts and phraseologies are still evolving, and need to be refined. Perhaps, some abstraction and confusion owing to lack of conceptual clarity is inevitable at the present juncture. The following definitions excerpted from OECD $(<2-13>)$ web pages would suffice for the time being.

Knowledge Management: KM practices have always existed in organizations to make decisions and to produce goods and services. What has changed is the weight of knowledge as a source of wealth-creation compared to other factors of production; knowledge has become a critical determinant of competitiveness for both private and public sectors. The knowledge-intensive economy implies a need for faster adaptation to accelerated change in the environment of public policies and service delivery. Governments will have to be more reactive, and deliver services closer to the customer. Thus, knowledge management represents a management modernization challenge for 
the public sector, which involves adapting classic management tools in a way that systematically promotes knowledge sharing.

This includes, inter alia:

- Improving human capital (flattening rigid pyramidal hierarchies, linking performance pay and promotion to knowledge sharing)

- Consolidating social capital: Fostering local community-based initiatives for poverty eradication (through Self Help Groups), creating a socio-political climate conducive to social capital formation by resolving gender issues and encouraging grass-roots political participation

- Adapting organizational capital (intranets, computerized databases)

- Networking to strengthen connections with private firms, research institutes, universities (promoting public-private partnerships)

KM-centric e-governance initiatives are being propelled by the availability of ICT tools that allow new ways for institutions to work. Such initiatives are capable of reaching out to realms beyond the confines of simple e-governance. Indeed, KM uses not only ICTs but also low-tech; communications tools, with its scope extending beyond internal decision making and delivery of services, to roles that encompass creation and availability of strategic knowledge. By the same token, e-governance extends beyond KM as it can increase a government's legitimacy, the quality of public decisions and service delivery, and promote citizen's contribution to public policy issues and decision-making.

KM and Public Policy Interventions: Effectively supporting the above governance work with KM concepts and tools requires a comprehensive re-think on management of know-how, domain expertise, information resources and knowledge bases. At the same time, the specific problems of public administration and governance (e.g. data protection, security, trustworthiness etc) need to be taken into account. Transition to e-Democracy and e-Government entails modernization and re-organization of governance work, its legacy systems and responsibilities. This has a significant impact on the distribution and shape of knowledge in the respective domains. Besides, when introducing new IT into a specific administration, past knowledge, -- based on which decisions would have been made, why they have been made and how have problems been solved --, represents a "valuable knowledge resource" for future changes. Support for collection, elaboration and accessibility of such domain and project knowledge (or, to be precise we may call it "Public Policy Intervention (PPI)-knowledge" needs to be designed properly. This entails monitoring and evaluation of effectiveness (success/ or lack of it) for each PPI, both at micro and macro levels across a span of time, termed "PPI-history", in juxtaposition with specific "Development Contexts".

\subsection{Governance Technology (Knowledge) Portals}

Overall, Governments are trying to take advantage of the latest technologies for value-added transaction driven portals and achieve cost savings. Typically, and naturally, they are not only addressing processes/ routines that are repetitive, drudgerous and those involving communication, but also decision entailing multi-department process flow paths, whereby their transfer to the web can make a noticeable differ- 
ence without big changes in the existing work practices or IT infrastructure. The traditional techniques of organization, work and process flow methods/ studies are finding a niche in this category of Portals. These Portals mostly fall into one of three categories:

- Intranet Applications that allow data to be gathered, processed and shared in new and more efficient ways

- Extranets that link Government to Business Partners (citizens, customers, suppliers, stakeholders etc) bringing discipline and cost-savings to procurement; and

- Public websites that give Citizens a self-service channel for their dealings with Government

The Micro-Angle: Let us for instance, take the case of India. Considering the subcontinental size and diversity of a vast country like India, QOG concepts and awareness will need to be tested from a micro-angle among the poor in select test centers in the metropolitan, urban and rural India, with a select cross-section of Politicians, Judicial and Legal luminaries, Captains of Industry, Beauracrats, Civil society and the NGOs, as also of Opinion Builders, Advertising and Media Personalities, Civil Society and the NGOs as to their expectations of QOG for India. An appropriately designed questionnaire and sampling methodology can be used to ascertain popular expectations on QOG and QOL (Life), and how people are expecting the Government to respond to their needs on particular issues.

E-Gov Portals: As system architectures currently in vogue demonstrate, e-Gov portals represent global entry points to many different local services from distinct public service providers. Customers as well as public authorities can access these offers via the Internet or even while on the move via devices such as mobile phones, handhelds etc. This forms the external, or customer-focused view of public services. From a government-specific perspective (the internal view), the services are considered as the sequence of process steps that must be performed by the overall system in order to fulfill customer requirements. Bringing together these two points of view is currently an important issue in the modeling of public services delivered through a global single-point access orientation. Several key aspects have to be addressed in order to meet this requirement:

- Applying a holistic concept to modeling public services

- Finding an appropriate mapping terminology

- Developing integrated service models that cover both the front-office (portal) and back-offices

- Adequate merging of service models with the technical components of the platform (e.g., interoperability)

- Applying a user-centric and service-centric development approach.

Virtually all e-Governance technologies are already working for e-commerce. For example, Enterprise Resource Planning (ERP), Customer Relationship Management (CRM) and Supply Chain Management (SCM), Data Warehousing and Mining (DWM), Business Intelligence, Internet Procurement and Payment Systems --, all are available now, and need little adaptation for e-Governance purposes. Likewise, security protocols, multi-layered firewalls and public key infrastructures needed for authentication and protection of data are already available off the shelf. Even the vendors, always keen to offer their own patent solutions agree that technology is not a 
barrier to introduction of e-Governance. So long as the e-Gov Technology Portals operate as humble learning organizations, one might rest assured that the cause of QOG is well served.

Learning with a TQM Approach: e-Governance is a learning process, whereby Quality Assurance (QA) procedures and methodologies could be devised and implemented appropriately using Total Quality Management (TQM), Comptency Maturity Model $(C M M)$ approaches. There is scope for TQM/ CMM processes in the following Governance areas which generally tend to evince some system/ process quality deficits:

Citizen vs Customer: In the competitive, liberal global scenario of goods and services, Governments must desist from indulging in monopolistic practices, relegating citizens' (cosumers/ customers) interest to the back burner. Availability of a speedy, decentralized legal system to protect consumer interest is critical.

Participative Processes and Transparency: Most developing countries are fraught with Governance related systemic and/ or process problems because of which only a fraction of benefits meant for customers (citizens) trickle down as intended. People are part of these processes and it is the quality of human resources that make a difference in delivering QOG and other overall development outcomes. TQM requires that such processes be analyzed with a quality slant in mind, improved constantly by introducing checks and balances for control and transparency from time to time. Long and arduous, such tasks can be successfully implemented only by involving people, enabling them to improve process quality through training and development, promoting a work ethic that creates a sense of pride and belonging (not alienation) to the community. These in essence are the kind of "Participative Processes" that should be accorded the highest priority.

Improve Organization, Systems \& Leadership: Often, it is systems, not human, failure, that inhibit Governments' ability to provide quality services. Quality drives pride and satisfaction. Strong leadership is responsible for relentlessly striving to improving systems and work culture, motivating people by inculcating pride in individual as well as team work, thereby enabling them perform better and do a quality job. Committed and responsible leadership must provide motivation by continued education and training, build trust through effective rewards and punishments so as to empower upright officials in discharging assigned duties without fear or favor. TQM dynamics in eGovernance should percolate like in a brick and mortar dispensation, and the implications of such dynamics must be public knowledge.

Citizen Charter: Governments can come out with a "Citizen's Charter" proclaiming what citizens can expect from e-Governance endeavors, and must promise to deliver the same within a timeframe. Unless backed up by quality initiatives as cited above, Citizens Charters would not evoke much enthusiasm and only remain on paper.

\subsection{The Concept of E-gov Toolkits}

"e-Governance Toolkits" with a canvass of cross functionalities that reflects the highest common factors affecting Quality of Life at Nation/ State, Provincial and Local levels in relation to QOG Missions/ Themes must be promoted and marketed to find prominent market niches. "Weaving" the myriad dimensions of Quality of Life (QOL) into a wide assortment of e-Gov Toolkits represents a major challenge in this regard. It may be too ambitious at the very outset of an e-governance initiative to live up to the exacting expectations such as those aroused by a "QOG" mission-driven e-Governance portal. A 
beginning can be made, however, by profiling different "e-Governance Toolkits" to suit typical requirements at national, provincial and local (village) levels in a sort of R\&D endeavor as it were. This entails identification of factors that significantly explain poverty reduction outcomes relative to the peculiarities of each developing country, or subnational (provincial/ local) level entities within each, and putting together solutions for the same. Such processes, being iterative, entail the design of an assortment of $e$-Gov Toolkits, and cannot be construed as a panacea. The e-Gov Toolkits, updated both for strategy and content, via interactive networking and web-enabled public policy advocacy, can draw analogies, for example, from the assortment intensive standards and specials product program (*) of Sandvik $A B$, Sweden.

$e$-Gov Toolkits will need to be developed, to serve both as diagnostic and treatment models, on the following lines:

1. Diagnostic Toolkits (D-Toolkits): To diagnose the Governance process deficiencies vis-à-vis World Bank's Quality of Growth norms (to be developed case by case) as pre-set criteria; and

2. Treatment Toolkits (T-Toolkits): To recommend appropriate e-Governance treatments, given the issues at hand and problems to be resolved.

The Analogy of an Assortment Intensive Product Program: The product and R \& D programs of the Swedish multinational Sandvik Aktiebolog, Sweden may be cited here. (Sandvik Asia, Pune (India), where the Senior Author of this Paper worked as a Marketing Services Staffer, is an important subsidiary of Sandvik AB, Stockholm). Their standard product program, an assortment intensive, high-tech product range of Tungsten Carbide T-Max Metal Cutting Tools, Inserts and Spares, -- in Turning, Milling and Drilling application areas --, running into over 2,500 items is a matter of corporate pride and image for the Sandvik group. Bulk of them is manufactured as part of a standard products program comprising different styles, tool geometries and carbide grades, and some to custom-built engineering specifications. Each tool item: holder/ insert/ spare is coded into a 24-digit generic coding system that uniquely identifies the product in the standard program with a level of disaggregation stretching up to styles, tool (cutting edge) geometries, carbide grades and the metal cutting application areas.

Sandvik has a strong bias on planning, performance monitoring, with vast investments in research and development built in as a deliberate strategic edge. The principals Sandvik AB, Sandviken, Sweden, as the world leader in the field, control their global stocking and inventory operations through sophisticated computerized systems, regular assortment analyses of their standard program in order to help maintain an optimum stock turnover ratio as well as a desired delivery security, the two balancing factors in the finished goods inventory management of assortment intensive product lines.

\subsection{Methodologies Akin to Statistical Design of Experiments}

The dichotomy of Toolkits as "D" and "T"-type will enable e-Governance practitioners with knowledge of the kind of treatments that could provide the best fit, given the resource endowments and public policy environment contexts (at hand/ encountered), and the problems to be resolved (as identified by "Diagnostic Toolkits). To be 
structured by Specialists in Development Economics, the T-Type Toolkits will incorporate experiential knowledge that encompasses resource endowment factors such as natural: geographic, soil and climatic conditions, human resource development level (education and literacy), the macro-micro dimensions of local issues, the authority of administrative unit responsible for governance. In juxtaposition to these data must be the Governance problem in question with an evaluation of achievements made against sustainable levels of QOG outcomes as diagnosed by the D-Type Toolkits. in in a "Synthesis Matrix". Such experiential learning also lends itself to knowledge of scalability / replicability as well of the e-Gov Toolkits. Through a persistent R\&D process, e-Gov Toolkits can be perfected as a standard product program of knowledge products.

\subsection{KM-Based E-governance Toolkits}

Experiential knowledge about the success or failure of specific e-development interventions constitute in essence the building blocks of KM-based Development policy Interventions. KM-based toolkits aimed at better concert and coordination in "priming" e-governance at the grass-roots level for achieving development outcomes and ensconcing systems capable of securing their integration into higher Governance echelons is most likely to be the future trend in Governance technology. With KMbased value enhanced Portals, which, perhaps, can be operated efficiently by private entrepreneurship, besides the above, Artificial Intelligence (Media Lab, MIT), Business Intelligence and combinations of these should work.

Toolkits are Knowledge Products: Quality assurance methods based on TQM Process methodologies can be devised to address the e-learning challenges of devising and perfecting e-Government Toolkits. Considering that QOG problems faced by developing countries are variegated, a wide "Assortment of Toolkits", devolving on the central concept of a phased realization of QOG outcomes can be devised to suit strategic e-development and thence the e-Governance needs at various echelon levels. To be successful, e-Gov entrepreneurs should take care to diligently scan local development environment and its interface with the hierarchical level constraints and opportunities (in a supply-demand scenario analysis as it were) and duly incorporate the insights in the development of e-Governance Toolkits:

1. The learning process involved in perfecting Toolkits is akin to an R\&D effort. The interactive power of the Internet, the multi-media, and the networking and wireless technologies can be harnessed in two major domains, viz., (i)-An Assortment Intensive e-Governance Toolkit Product Program; and (ii)-A Web mounted ERP, CRM and management of the Toolkits Program, both provide a launch pad for a Knowledge-based Initiative. A Micro-to-Macro-Economic Planning Interface of considerable import can then be mapped out re-affirming thereby that economic planning is a bottom-up rather than a top-down exercise.

2. In order to serve as useful instruments for ushering in e-Governance, the effectiveness of each e-Gov Toolkit as an efficient, replicable treatment for different eGovernment needs should be monitored across a "launch to maturity product cycle", consistent with the market demand (for e-Gov Products) identifiable as part of an assortment intensive product program with extensive $R \& D$ back-up, analo- 
gous to the standard product program of the Swedish multinational Sandvik AB as mentioned above.

Assortment Intensive e-Gov Toolkits: The variables that can be woven into an $e$ Gov Toolkit Product Program should be chosen with good care in a manner encompassing all possible situations, bearing in mind that e-Governance is a complex process, as also the kind of QOG outcomes which the Country, State/ District/ Village/ Community would wish to see addressed. It would take a good number of iterations to develop an imaginative $e$-Gov Standard Product Program consistent with the $e$-Gov market requirements. The coding structure might take into account the following, illustrative but not exhaustive, dimensions and product attributes that seek to describe the e-Gov Toolkits:

(based on knowledge of India's current governance hierarchies and situational contexts)

\subsubsection{Planning Philosophy}

Approach Used (Employment Oriented/ Investment and Growth-oriented, Top-down/ Bottom-up etc), resource endowments, political clout of current regime holding the reins of governance.

\subsubsection{Contextual}

Supply Side: Year of Structuring, Political Entity (Country, State/ District/ Village/ Block Community (with a pre-specified remit of Administrative Authority)

Demand Side: Persona / Orientation (Diagnostic or Treatment types) Local development issues (State/ District. / Village/ Block/ Panchayat/ Community

\subsubsection{Developmental}

Local Development Planning Machinery, bottom-up as against top-down, Capacity Building, Social Capital, Gender, Women's Self Help Groups, Micro-finance etc

\subsubsection{Technical}

E-Platform, Networking (outreach and potential) Middleware, Relational Database Management (RDBMS), Enterprise Resource Planning (ERP), Business Intelligence (BI) data-mining, transaction payment processing, business modeling, e-security.

As one-size does not fit for all, within the ambit of Quality of Life missions/ themes on which the e-Governance Toolkit(s) devolve, it is important to design $F u$ turistic Toolkits, as far as possible, as down-to-earth simple as they must be easy-tooperate instruments for developing country $G 2 B$ environments. Such products entail intensive $\mathrm{R} \& \mathrm{D}$ backed by experiential learning, incorporating in-built KM approaches, and can find excellent markets worldwide. Looking back, it might be admitted that ventures of the kind envisaged above are fraught with tremendous complexity. Hence it is better to start with a low ambition level, perhaps using a "cut and sew" approach to deal with turbulence. Rigor in identifying the mission critical attributes of toolkits in each PPI is an important task in this respect. 
A Networked Monitoring Mechanism that connects panels of select economists, legal, judicial specialists and Government experts will be an important feature of operating the e-Governance Service Sites. Innovative "Design of Experiments Approaches in Social Sciences" aimed at securing Development Solutions (using the power of ICTs) can be tried in this regard. While such an endeavor should minimize the mismatch between policies and micro-level development outcomes ought to be engendering "Quality", as far as the Government Portals are concerned, the tasks to be undertaken are fraught with complexity, entailing tremendous coordination and concert. Thanks to XML and Business Intelligence Techniques enabling in-depth relational data mining, new e-Gov ventures trying these techniques, we surmise, must be already on the horizon.

Dissemination Mechanisms: Once toolkits are developed, they should be linked to websites at national and supranational levels in the domains of Development Economics/ Governance Technology Research etc. Linking them to all existing eGovernance sites on as "reciprocal knowledge exchanges" will go a long way in furthering a "collaborative e-learning process" with intrinsic synergies. Periodic announcements can be made on networked websites, as also on web pages of international organizations/ conferences dealing with development research such as of the World Development Institute, Washington, World Bank Development Forum, the UNDP's Millennium Development Goals, International Development Research Center (IDRC), Organization for Economic Cooperation and Development (OECD), World Economic Forum (WEF), Global Development Network (GDNet), International Institute of Communications Development (IICD), Poverty Net.org etc. for a worldwide audience.

\section{References}

1. David Dollar \& Aart Kray, both Nobel Laeurates in Economics, Vonod Thomas (World Bank Researchers).

2. Organization for Economic Cooperation and Development (OECD), Paris

3. The OECD Public Management service's work on knowledge management in the public sector looks at the consequences of the "knowledge intensive economy" on the role and functioning of the public sector, and takes stock of initiatives in OECD countries to face these challenges.

4. What's new on KM (Source: OECD Webpages)

5. Conclusions of the Survey on knowledge management (KM) practices (30-Jul-2003)

6. PUMA launched a survey on KM practices in central ministries in OECD countries. The survey looked at where public organizations stand in terms of KM and made cross-national and cross-sectoral comparisons of their implementation of KM strategies. The conclusions are available in the attached report.

7. Public Management (PUMA) Committee, "The Learning Government" - Introduction and Draft Results of the Survey of Knowledge Management Practices in Ministries/ Departments/ Agencies of Central Governments (Published on 17 March 2003)

8. OECD Symposium on the Learning Government from 03-Feb-2002 to 04-Feb-2003

9. On February 3-4, 2003, OECD/GOV held a symposium on "The learning government: Managing knowledge in central government".

10. Survey of government knowledge management practices (06-Aug-2002) 
11. A survey of knowledge management $(\mathrm{KM})$ practices in central government ministries/departments/agencies was launched in January 2002. The results of the survey were discussed at the Symposium on "The Learning Government" which took place at OECD headquarters in Paris on 3-4 February 2003.

12. Conclusions of a high-level Forum (11-Jul-2001)

13. 'Learning-By-Comparing' Experiences from Private Firms and Public Organizations" hosted by the Danish Government and organized by CERI, with Learning Lab Denmark, and PUMA. 